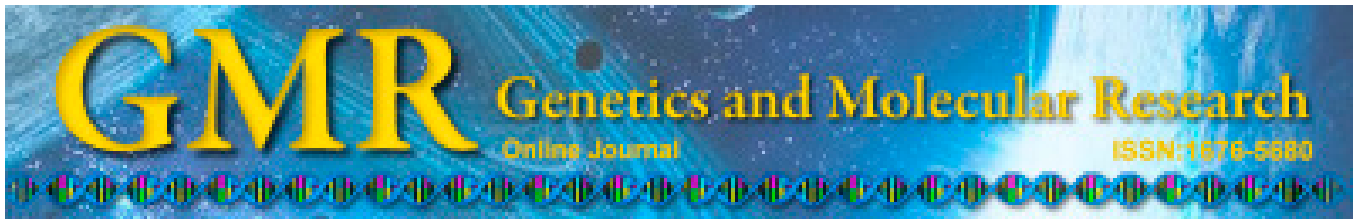

\title{
Associations between TNF- $\alpha$ polymorphisms and susceptibility to rheumatoid arthritis and vitiligo: a meta-analysis
}

\author{
Y.H. Lee ${ }^{1}$ and S.C. Bae ${ }^{2}$ \\ Korea University College of Medicine, Seoul, Korea \\ Seoul, Korea \\ Corresponding author: Y.H. Lee \\ E-mail: lyhcgh@korea.ac.kr \\ Genet. Mol. Res. 14 (2): 5548-5559 (2015) \\ Received July 14, 2014 \\ Accepted November 24, 2014 \\ Published May 25, 2015 \\ DOI http://dx.doi.org/10.4238/2015.May.25.6
}

${ }^{1}$ Division of Rheumatology, Department of Internal Medicine,

${ }^{2}$ The Hospital for Rheumatic Diseases, Hanyang University Medical Center,

\begin{abstract}
We investigated whether the tumor necrosis factor- $\alpha$ $(T N F-\alpha)$ promoter $-238 \mathrm{~A} / \mathrm{G}$ and $-308 \mathrm{~A} / \mathrm{G}$ polymorphisms are associated with rheumatoid arthritis (RA) and vitiligo susceptibility. MEDLINE and EMBASE databases and a manual search were used to identify articles in which $T N F-\alpha$ polymorphisms were determined in RA or vitiligo patients and controls. Meta-analysis was used to examine the associations between the $T N F-\alpha-238 \mathrm{~A} / \mathrm{G}$ polymorphism and RA and vitiligo using the allelic contrast and dominant models. Fifteen studies (10 RA and 5 vitiligo) involving 3678 cases and 4400 controls were considered. We observed an association between the $T N F-\alpha-238$ A allele and RA when all subjects were considered [odds ratio $(\mathrm{OR})=$ $0.686,95 \%$ confidence interval $(\mathrm{CI})=0.476-0.968, \mathrm{P}=0.043]$. After stratification by ethnicity, we found no association between the $T N F-\alpha$ $-238 \mathrm{~A}$ allele and RA in European or Asian populations. We observed no association between the $T N F-\alpha-308$ A allele and vitiligo (OR $=1.787$, $95 \% \mathrm{CI}=0.894-3.573, \mathrm{P}=0.101)$. However, the adjusted OR by the
\end{abstract}


trim-and-fill technique was significant $(\mathrm{OR}=2.064,95 \% \mathrm{CI}=1.138$ 3.743). After stratification by geographic continent, the $T N F-\alpha-308$ A allele was significantly associated with vitiligo in Middle Eastern populations $\left(\mathrm{OR}=1.569,95 \% \mathrm{CI}=1.224-2.013, \mathrm{P}=3.8 \times 10^{-5}\right)$. The $T N F-\alpha-238 \mathrm{~A} / \mathrm{G}$ polymorphism was associated with RA susceptibility, and the TNF- $\alpha-308 \mathrm{~A} / \mathrm{G}$ polymorphism may be a significant risk factor for vitiligo in Middle Eastern populations.

Key words: Meta-analysis; Polymorphism; Rheumatoid arthritis; Tumor necrosis factor; Vitiligo

\section{INTRODUCTION}

Rheumatoid arthritis (RA) is a chronic inflammatory disease that mainly occurs in synovial joints and affects up to $1 \%$ of adults worldwide (Harris, 1990). Vitiligo is a progressive depigmentation disorder characterized by the loss of functional melanocytes from the epidermis and affects 1-2\% of the world's population (Mollet et al., 2007). Although the etiology of RA and vitiligo remains unknown, a genetic component has been associated with the susceptibility to RA and vitiligo (Choi et al., 2006).

Tumor necrosis factor- $\alpha$ (TNF- $\alpha$ ) is a potent pro-inflammatory cytokine that plays important roles in inflammatory and immune responses, including those observed in RA and vitiligo (Rooney et al., 1995). TNF stimulates cytokine production to enhance the expression of adhesion molecules and increase neutrophil activation. The $T N F$ gene is located on chromosome 6 , within the human leukocyte antigen class III region, and several single-nucleotide polymorphisms have been identified in its promoter (Allen, 1999). Of these, the G-to-A substitution at positions -308 and -238 have been intensively studied, and some researchers have suggested that these allelic variations have functional significance (D'Alfonso and Richiardi, 1994).

Several studies have examined the potential contributions of the $T N F-\alpha-238 \mathrm{~A} / \mathrm{G}$ (rs361525) and $-308 \mathrm{~A} / \mathrm{G}$ (rs1800629) polymorphisms to the susceptibility to RA and vitiligo (Brinkman et al., 1997; Vinasco et al., 1997; van Krugten et al., 1999; Yen et al., 2001; Fabris et al., 2002; Zwiers et al., 2004; Correa et al., 2005; Rodríguez-Carreón et al., 2005; Yazici et al., 2006; Namian et al., 2009; Emonts et al., 2011; Laddha et al., 2012; Salinas-Santander et al., 2012; Al-Harthi et al., 2013; You et al., 2013). However, the findings of these studies have been inconsistent, likely because of small sample sizes and low statistical power. Furthermore, allelic frequencies in genes often differ substantially between ethnicities or geographical regions; therefore, ethnicity/continent-specific association studies are needed to determine genetic associations in different populations (Lee et al., 2007, 2010, 2011). In the present study, we conducted a meta-analysis to determine whether the $T N F-\alpha-238 \mathrm{~A} / \mathrm{G}$ and $-308 \mathrm{~A} / \mathrm{G}$ polymorphisms were associated with susceptibility to RA and vitiligo in different populations.

\section{MATERIAL AND METHODS}

\section{Identification of eligible studies and data extraction}

A literature search was conducted to identify studies that examined associations between $T N F-\alpha$ polymorphisms and RA or vitiligo. The MEDLINE and EMBASE citation in- 
dexes were used to identify articles published through April 2014, in which the presence of $T N F-\alpha$ polymorphism was determined in RA or vitiligo patients and controls. Combinations of key words such as "TNF- $\alpha$ ", "TNF- $\alpha-238$ ", "TNF- $\alpha-308$ ", "polymorphism", "rheumatoid arthritis", "RA", and "vitiligo" were entered as both Medical Subject Headings and text words. In addition, all references were reviewed to identify additional studies not indexed by MEDLINE and EMBASE. Studies were included in the analysis if they were: 1) case-control studies; 2) included patients with RA or vitiligo; and 3) included genotype data for the $T N F-\alpha$ $-238 \mathrm{~A} / \mathrm{G}$ or $-308 \mathrm{~A} / \mathrm{G}$ polymorphism. No language restrictions were applied. Moreover, the following studies were excluded: 1) studies containing overlapping data;2) studies in which the genotypes could not be ascertained; and 3) studies in which family members had been included and the analysis was based on linkage considerations. Information on the methods and results of the analyses were extracted from the original studies by 2 independent researchers. Disagreements were resolved by consensus or a third researcher. The following information was extracted from each study: 1) author, 2) year of publication, 3) ethnicity and geographical location of the study population, 4) numbers of cases and controls, and 5) the genotype and allele frequencies of the $T N F-\alpha$ polymorphism.

\section{Evaluation of statistical associations}

We examined the contrast between the allelic effect of the A allele and the $\mathrm{G}$ allele, and examined the contrast between the $\mathrm{AA} / \mathrm{AG}$ and $\mathrm{GG}$ genotypes to analyze the dominant effect of the A allele. The point estimates of odds ratios (ORs) and their $95 \%$ confidence intervals (CIs) were determined for each study. Cochran's Q-statistics were used to assess within- and between-study variations and heterogeneities (Higgins and Thompson, 2002). The heterogeneity test was used to assess the null hypothesis to ensure that all studies were evaluating the same effect. When a significant $\mathrm{Q}$-statistic $(\mathrm{P}<0.10)$ indicated heterogeneity across studies, the random-effects model was used for the meta-analysis; when heterogeneity across studies was not indicated, the fixed-effects model was used. Fixed-effects meta-analysis assumes that genetic factors have similar effects on disease susceptibility across all studies, and that observed variations between studies result from chance alone (Egger et al., 1997b). The random-effects model assumes that different studies show substantial diversity and assesses both within-study sampling errors and between-study variance (DerSimonian and Laird, 1986). We also quantified the effect of heterogeneity by using $I^{2}=100 \% \times\left(Q-d_{\text {.f. }}\right) / Q$ (Higgins and Thompson, 2002). $I^{2}$ ranges between 0 and $100 \%$ and represents the proportion of inter-study variability that can be attributed to heterogeneity rather than to chance. $I$ values of 25,50 , and $75 \%$ were defined as low, moderate, and high, respectively. Statistical manipulations were performed using the Comprehensive Meta-Analysis software (Biostat, Englewood, NJ, USA). The powers of the studies were computed as the probabilities of detecting associations between $T N F-\alpha$ polymorphisms and RA at a level of significance of 0.05 , assuming a small effect size. Power analysis was performed using the statistical software G*Power (http:// www.psycho.uni-duesseldorf.de/aap/projects/gpower).

\section{Evaluation of heterogeneity and publication bias}

The chi-square test was used to determine whether the genotype frequency observed in controls was in Hardy-Weinberg equilibrium (HWE). We performed sensitiv- 
ity analysis by excluding studies in which the genotype distribution in controls was not consistent with HWE, as deviation from HWE among controls suggests biased control selection or genotyping errors. To examine the potential source of heterogeneity observed in the meta-analysis, meta-regression was performed using the following variables: ethnicity, publication year, and sample size. A funnel plot of effect size against standard error was used to detect publication bias. A funnel plot should be asymmetrical in the case of no publication bias. However, this method requires a range of studies of different sizes and involves subjective judgment; therefore, we evaluated publication bias using Egger's linear regression test (Egger et al., 1997a), which measures funnel plot asymmetry using a natural logarithmic scale for ORs. When asymmetry was indicated, we used the trim-andfill method to adjust the summary estimate for the observed bias.

\section{RESULTS}

\section{Studies included in the meta-analysis}

Seventy-six relevant studies were identified, and 18 were selected for full-text review based on their titles and abstracts. Three were excluded because no extractable genotype data or family data were included. Thus, 15 studies met our inclusion criteria (Brinkman et al., 1997; Vinasco et al., 1997; van Krugten et al., 1999; Yen et al., 2001; Fabris et al., 2002; Zwiers et al., 2004; Correa et al., 2005; Rodríguez-Carreón et al., 2005; Yazici et al., 2006; Namian et al., 2009; Emonts et al., 2011; Laddha et al., 2012; Salinas-Santander et al., 2012; Al-Harthi et al., 2013; You et al., 2013). Ten studies examined RA and 5 examined vitiligo. In total, the studies included 3678 cases and 4400 controls (2151 cases and 2156 controls for RA, 1527 cases and 2244 controls for vitiligo) (Table 1). They consisted of 6 European, 2 Asian, and 2 Latin American studies in RA. Ethnicity-specific meta-analysis was conducted on these populations in RA. Vitiligo studies included 3 Middle Eastern, 1 Asian, and 1 South American study based on continent. Selected characteristics regarding the relationships found between $T N F-\alpha$ polymorphisms and RA or vitiligo are summarized in Table 1 . The statistical powers of these studies ranged from 24.6 to $99.2 \%$, and 3 studies had powers greater than $80 \%$ (Emonts et al., 2011; Laddha et al., 2012; You et al., 2013).

\section{Meta-analysis of the association between the $T N F-\alpha-238 \mathrm{~A} / \mathrm{G}$ polymorphism and RA}

The meta-analysis revealed an association between the $T N F-\alpha-238$ A allele and RA when all subjects were considered $(\mathrm{OR}=0.686,95 \% \mathrm{CI}=0.476-0.968, \mathrm{P}=0.043)$ (Table 2, Figure 1). After stratification by ethnicity, the A allele was not associated with RA in European or Asian populations (Table 2). Meta-analysis of the AA+AG genotype showed the same pattern of results as for the $T N F-\alpha-238$ A allele. The meta-analysis indicated an association between the $\mathrm{AA}+\mathrm{AG}$ genotype and $\mathrm{RA}$ when all subjects were considered $(\mathrm{OR}=0.644,95 \% \mathrm{CI}$ $=0.432-0.962, \mathrm{P}=0.031$ ), but stratification by ethnicity revealed no association between the AA/AG genotype an RA in each ethnic group (Table 2). 


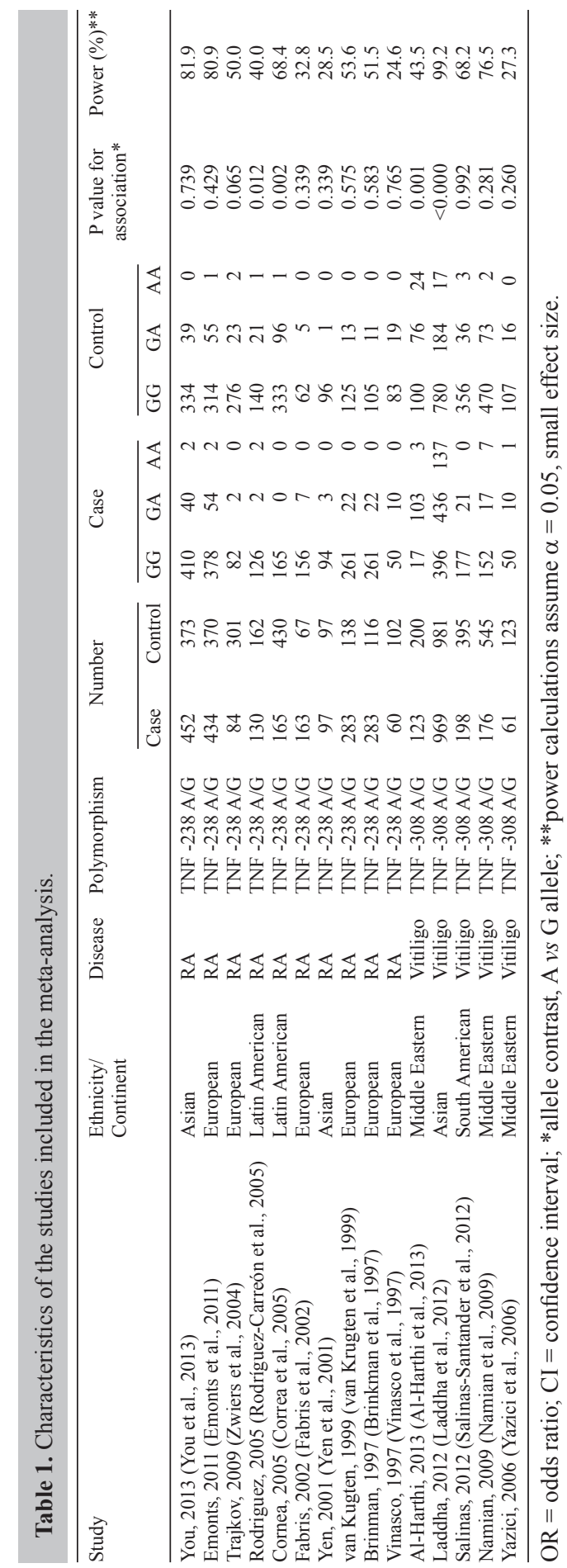


Table 2. Meta-analysis of the $T N F-\alpha-238 \mathrm{~A} / \mathrm{G}$ polymorphism and RA.

\begin{tabular}{|c|c|c|c|c|c|c|c|c|c|c|}
\hline \multirow[t]{2}{*}{ Polymorphism } & \multirow[t]{2}{*}{ Population } & \multirow[t]{2}{*}{ No. of studies } & \multicolumn{5}{|c|}{ Numbers Test of association } & \multicolumn{3}{|c|}{ Test of heterogeneity } \\
\hline & & & RA & Control & OR & $95 \% \mathrm{CI}$ & $P$ value & Model & $P$ value & $I^{2}$ \\
\hline \multirow[t]{4}{*}{ A vs $\mathrm{G}$ allele } & Overall & 10 & 2151 & 2156 & 0.686 & $0.476-0.968$ & 0.043 & $\mathrm{R}$ & 0.041 & 48.7 \\
\hline & European & 6 & 1307 & 1094 & 0.795 & $0.606-1.043$ & 0.098 & $\mathrm{~F}$ & 0.714 & 0 \\
\hline & Asian & 2 & 549 & 470 & 0.968 & $0.627-1.495$ & 0.885 & $\mathrm{~F}$ & 0.316 & 0.56 \\
\hline & Latin American & 2 & 295 & 592 & 0.079 & $0.003-1.871$ & 0.116 & $\mathrm{R}$ & 0.028 & 79.1 \\
\hline \multirow[t]{4}{*}{$\mathrm{AA} / \mathrm{AG} v s \mathrm{GG}$} & Overall & 10 & 2151 & 2156 & 0.644 & $0.432-0.962$ & 0.031 & $\mathrm{R}$ & 0.024 & 52.9 \\
\hline & European & 6 & 1307 & 1094 & 0.777 & $0.585-1.030$ & 0.079 & F & 0.772 & 0 \\
\hline & Asian & 2 & 549 & 470 & 0.921 & $0.587-1.445$ & 0.720 & F & 0.292 & 9.88 \\
\hline & Latin American & 2 & 295 & 592 & 0.061 & $0.003-1.062$ & 0.055 & $\mathrm{R}$ & 0.051 & 73.6 \\
\hline
\end{tabular}

$\mathrm{OR}=$ odds ratio $\mathrm{CI}=$ confidence interval; $\mathrm{F}=$ fixed-effects model; $\mathrm{R}=$ random-effects model, $\mathrm{RA}=$ rheumatoid arthritis.

\section{Study name}

\begin{tabular}{lcccc}
\hline & $\begin{array}{c}\text { Odds } \\
\text { ratio }\end{array}$ & $\begin{array}{c}\text { Lower } \\
\text { limit }\end{array}$ & $\begin{array}{c}\text { Upper } \\
\text { limit }\end{array}$ & P Value \\
& & & & \\
You, 2013 & 0.927 & 0.596 & 1.444 & 0.739 \\
Emonts, 2011 & 0.858 & 0.587 & 1.254 & 0.429 \\
Trajkov, 2009 & 0.257 & 0.060 & 1.090 & 0.065 \\
Rodriguez, 2005 & 0.309 & 0.124 & 0.771 & 0.012 \\
Correa, 2005 & 0.012 & 0.001 & 0.189 & 0.002 \\
Fabris, 2002 & 0.566 & 0.176 & 1.816 & 0.339 \\
Yen, 2001 & 3.031 & 0.313 & 29.401 & 0.339 \\
van Kugten, 1999 & 0.818 & 0.406 & 1.650 & 0.575 \\
Brinkman, 1997 & 0.813 & 0.387 & 1.704 & 0.583 \\
Vinasco, 1997 & 0.885 & 0.397 & 1.972 & 0.765 \\
& 0.686 & 0.476 & 0.988 & 0.043
\end{tabular}

\section{Odds ratio and $95 \% \mathrm{Cl}$}

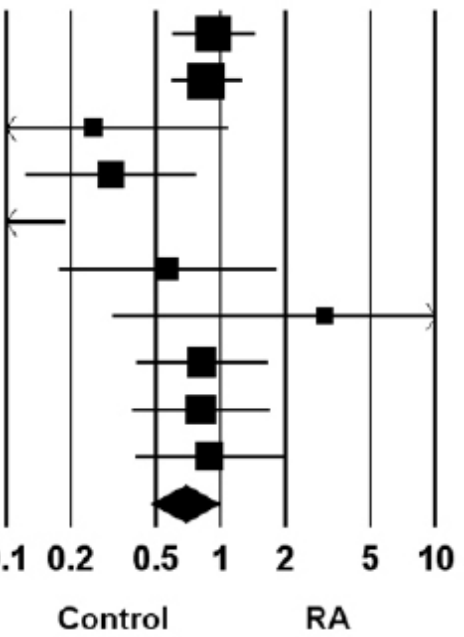

Figure 1. ORs and $95 \% \mathrm{CIs}$ from individual studies and pooled data for the association between the A allele of the $T N F-\alpha-238 \mathrm{~A} / \mathrm{G}$ polymorphism and RA in all study subjects.

\section{Meta-analysis of the association between the $T N F-\alpha-308$ A/G polymorphism and vitiligo}

The meta-analysis showed no association between the $T N F-\alpha-308$ A allele and vitiligo when all subjects were considered $(\mathrm{OR}=1.787,95 \% \mathrm{CI}=0.894-3.573, \mathrm{P}=0.101)$ (Table 3 , Figure 2). After stratification by continent, the A allele was significantly associated with vitiligo in the Middle Eastern group $\left(\mathrm{OR}=1.569,95 \% \mathrm{CI}=1.224-2.013, \mathrm{P}=3.8 \times 10^{-5}\right)$ (Table 3 , Figure 2). However, meta-analysis of the $\mathrm{AA}+\mathrm{AG}$ genotype showed no association between the AA+AG genotype and vitiligo (Table 3 ). 
Table 3. Meta-analysis of the $T N F-\alpha-308 \mathrm{~A} / \mathrm{G}$ polymorphism and vitiligo.

\begin{tabular}{|c|c|c|c|c|c|c|c|c|c|c|}
\hline \multirow[t]{2}{*}{ Polymorphism } & \multirow[t]{2}{*}{ Population } & \multirow[t]{2}{*}{ No. of studies } & \multicolumn{2}{|c|}{ Numbers } & \multicolumn{3}{|c|}{ Test of association } & \multicolumn{3}{|c|}{ Test of heterogeneity } \\
\hline & & & Vitiligo & Control & OR & $95 \%$ CI & $P$ value & Model & $P$ value & $r^{2}$ \\
\hline \multirow[t]{3}{*}{ A vs $\mathrm{G}$ allele } & Ove & 5 & 1527 & 2244 & 1.787 & $0.894-3.573$ & 0.101 & $\mathrm{R}$ & 0.000 & 94.1 \\
\hline & & 6 & NA & NA & 2.064 & 3 & $<0.05$ & $\mathrm{R}$ & NA & NA \\
\hline & Middle Eastern & 3 & 360 & 868 & 1.569 & $1.224-2.013$ & $3.8 \times 10^{-5}$ & $\mathrm{~F}$ & 0.491 & 0 \\
\hline \multirow{2}{*}{$\mathrm{AA} / \mathrm{AG} v s \mathrm{GG}$} & Overall & 5 & 1527 & 2244 & 2.269 & $0.941-5.471$ & 0.068 & $\mathrm{R}$ & 0.000 & 94.2 \\
\hline & Middle Eastern & 3 & 360 & 868 & 2.093 & $0.021-7.059$ & 0.234 & $\mathrm{R}$ & 0.000 & 91.2 \\
\hline
\end{tabular}

*Adjusted by trim-and-fill method, $\mathrm{OR}=$ odds ratio; $\mathrm{CI}=$ confidence interval; $\mathrm{F}=$ fixed-effects model; $\mathrm{R}=$ randomeffects model, NA = Not available.

A

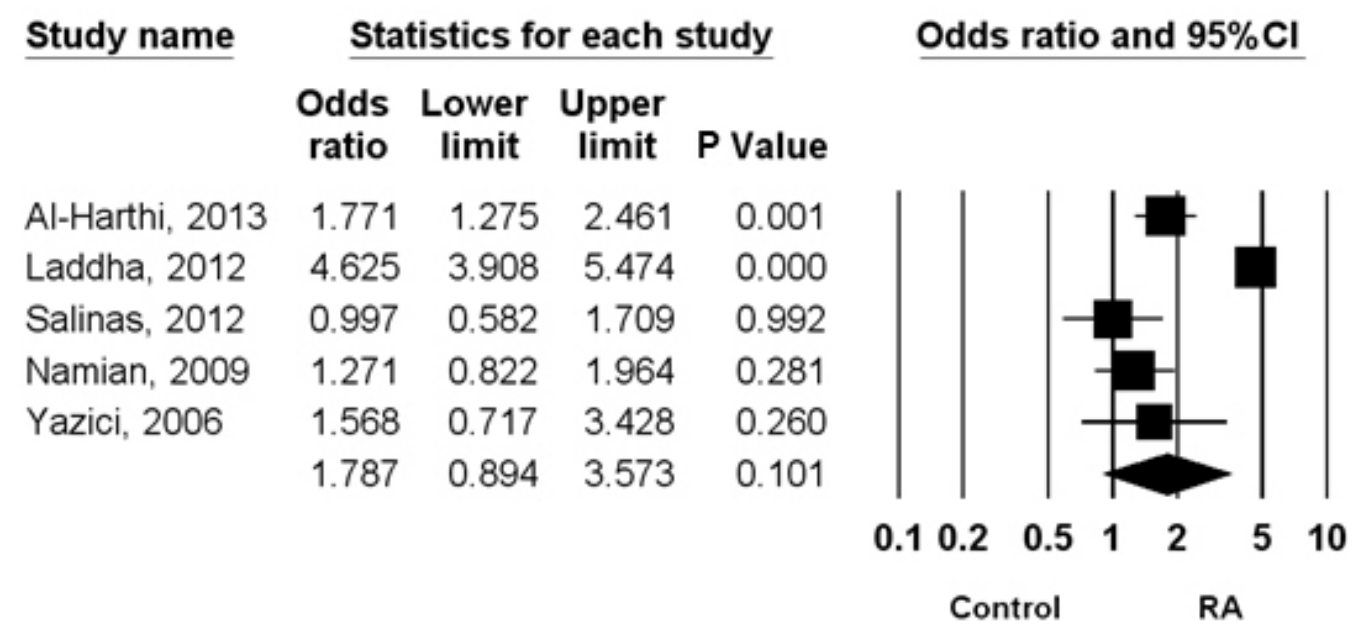

B

Group by Continent Study name

Asian

Asian Miiddle East

Miiddle East

Miiddle East

Miiddle East

South American

South American

$\begin{array}{lcccc} & \begin{array}{c}\text { Odds } \\ \text { ratio }\end{array} & \begin{array}{c}\text { Lower } \\ \text { limit }\end{array} & \begin{array}{c}\text { Upper } \\ \text { limit }\end{array} & \text { P Value } \\ \text { Laddha, 2012 } & 4.625 & 3.908 & 5.474 & 0.000 \\ & 4.625 & 3.908 & 5.474 & 0.000 \\ \text { AL-Harthi, 2013 } & 1.771 & 1.275 & 2.461 & 0.001 \\ \text { Namian, 2009 } & 1.271 & 0.822 & 1.964 & 0.281 \\ \text { Yazici, 2006 } & 1.568 & 0.717 & 3.428 & 0.260 \\ & 1.569 & 1.224 & 2.013 & 0.000 \\ \text { Salinas, 2012 } & 0.997 & 0.582 & 1.709 & 0.992 \\ & 0.997 & 0.582 & 1.709 & 0.992\end{array}$

Odds ratio and $95 \% \mathrm{Cl}$

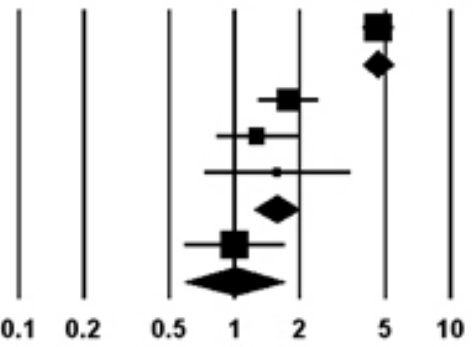

Control

Figure 2. ORs and 95\%CIs from individual studies and pooled data for the association between the A allele of the $T N F-\alpha-308 \mathrm{~A} / \mathrm{G}$ polymorphism and vitiligo in each geographical continent group. 


\section{Evaluation of heterogeneity and publication bias}

The distributions of genotypes in normal control groups were not consistent with HWE in 1 study on RA (Correa et al., 2005). However, excluding this study, the data did not materially affect our meta-analysis results regarding the associations between the $T N F-\alpha-238$ $\mathrm{A} / \mathrm{G}$ polymorphism and RA. Between-study heterogeneity was observed in meta-analyses of $T N F-\alpha$ polymorphisms and RA or vitiligo (Table 2 ). To examine the potential source of heterogeneity, meta-regression was performed. The results showed that ethnicity $(\mathrm{P}=0.021)$, but not publication year and sample size, significantly impacted the heterogeneity in the $T N F-\alpha-238$ A/G polymorphism in RA (Figure 3). Meta-regression analysis revealed that the continent ( $\mathrm{P}$ $<0.001)$, sample size $(\mathrm{P}<0.001)$, and publication year $(\mathrm{P}=0.005)$ contributed to the source of heterogeneity in the $T N F-\alpha-308 \mathrm{~A} / \mathrm{G}$ polymorphism in vitiligo (Figure 3). Egger's regression test showed evidence of publication bias in the meta-analysis of the $T N F-\alpha$ polymorphisms in RA and vitiligo (Egger's regression test $\mathrm{P}$ values $=0.086,0.044$ ) (Figure 4$)$. The adjusted OR by the trim-and-fill technique was not changed in RA, but became significant in vitiligo (OR $=2.064,95 \% \mathrm{CI}=1.138-3.743)($ Table 2$)$.

\section{A}

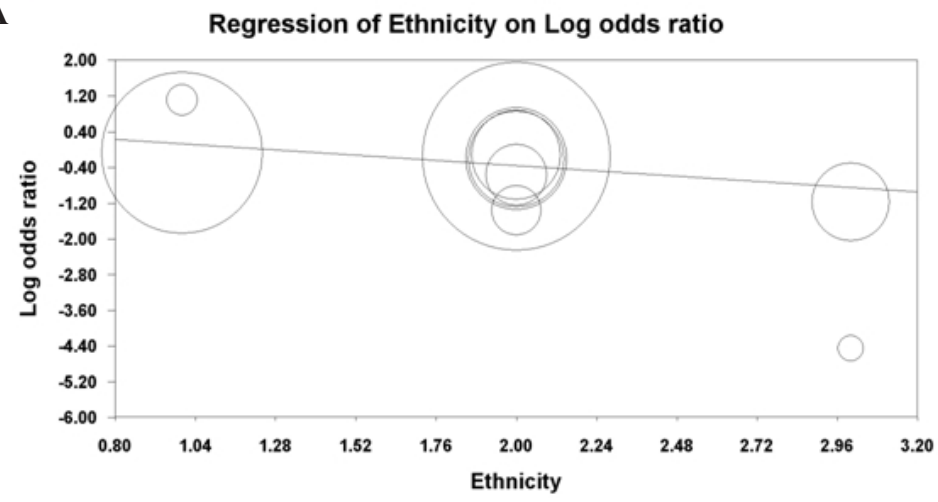

B

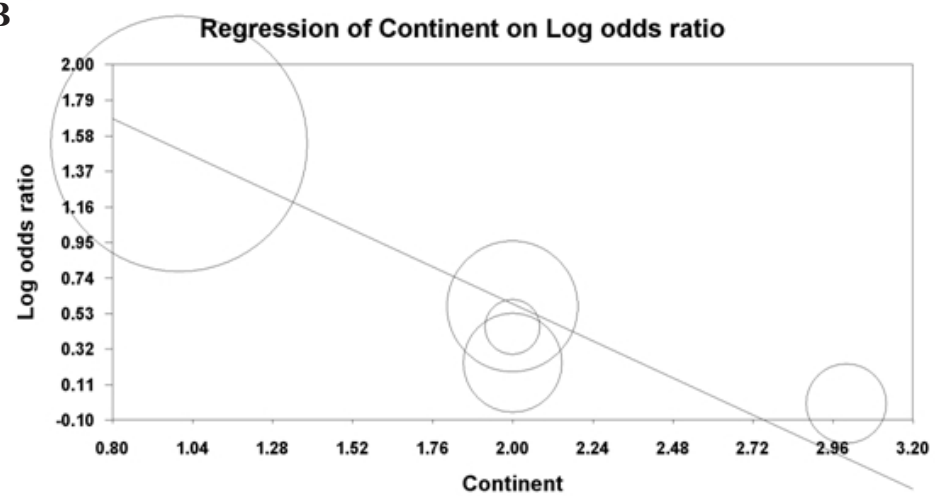

Figure 3. Meta-regression of (A) ethnicity on ORs of the $T N F-\alpha-238$ A allele in $\mathrm{RA}(\mathrm{P}=0.021)$, and $(\mathbf{B})$ continent on ORs of the $T N F-\alpha-308$ A allele effect in vitiligo $(\mathrm{P}<0.001)$. Each circle represents a study with a size proportional to the sample size. (A) Ethnicity 0 indicates Asian, 1 indicates European, and 2 indicates Latin American. (B) Continent 0 indicates Asia, 1 indicates South America, and 2 indicates the Middle East. 
A

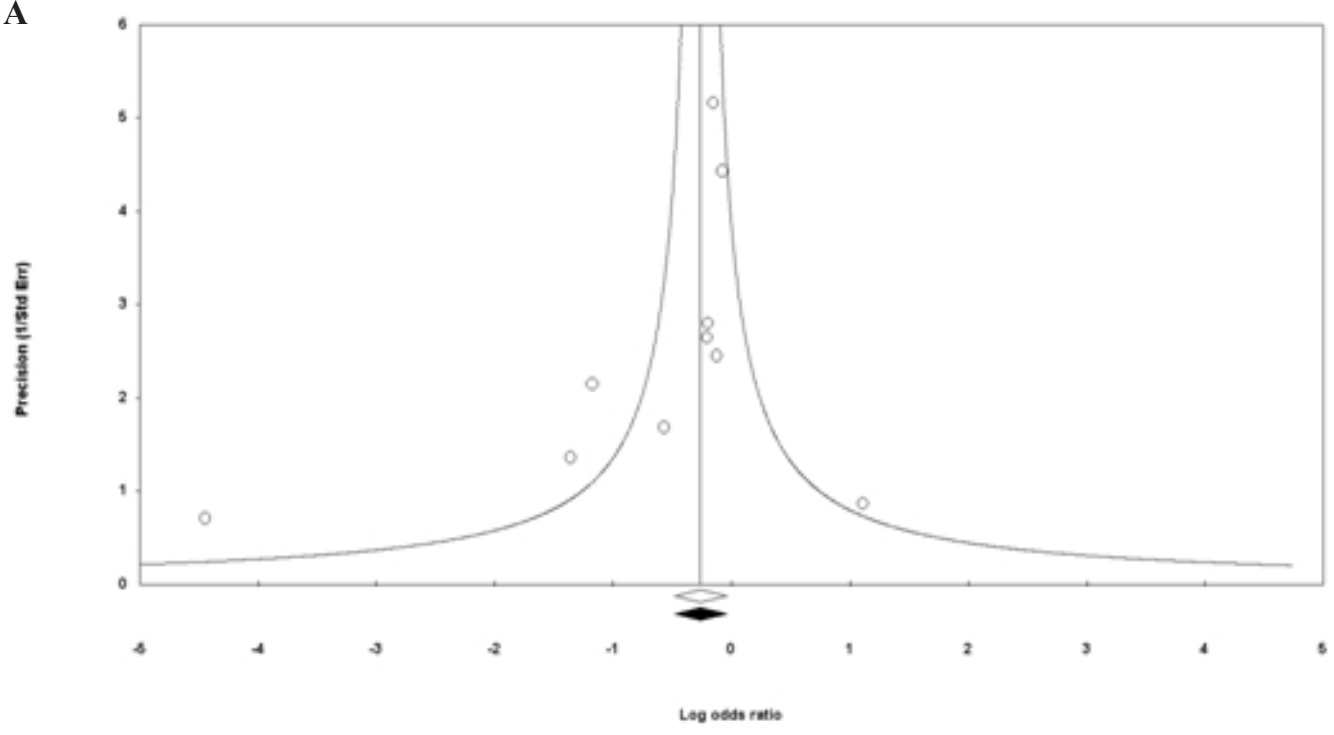

B

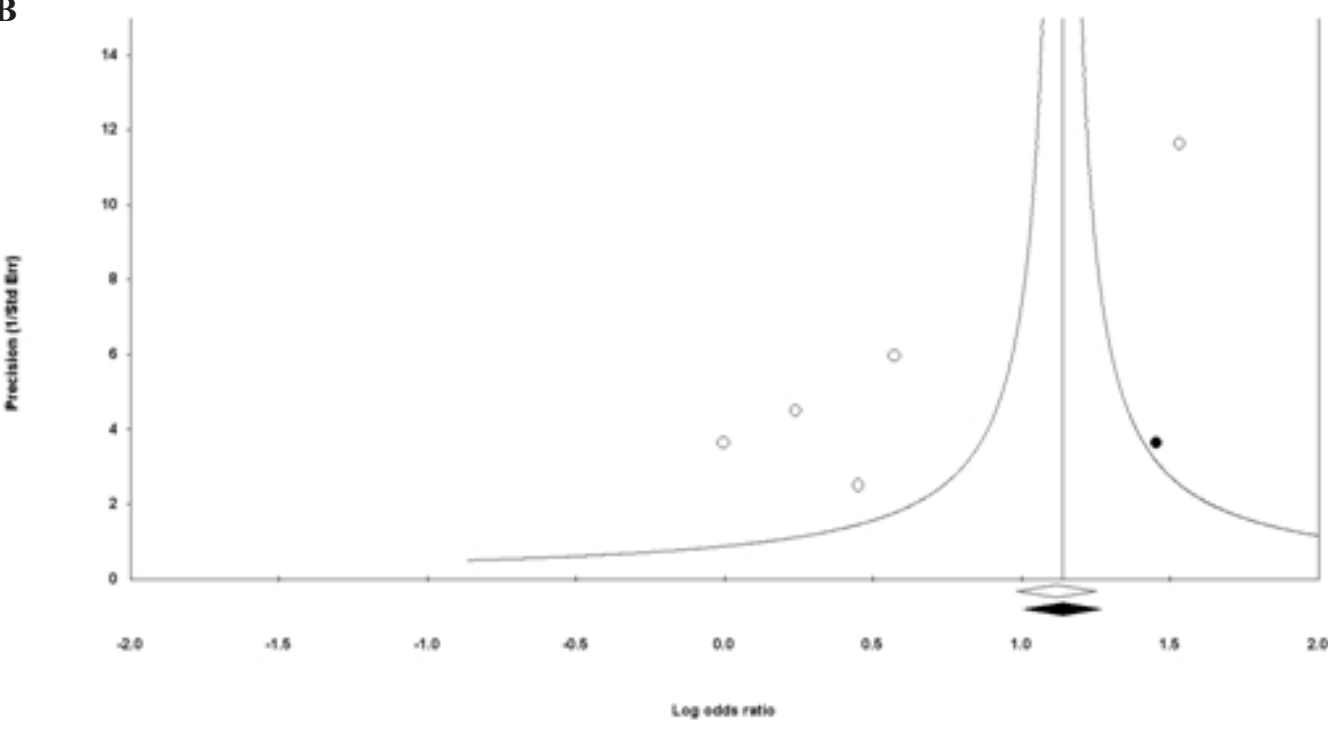

Figure 4. Funnel plot of studies on associations (A) between the TNF- $\alpha-238 \mathrm{~A}$ allele and RA, and (B) between the $T N F-\alpha-308$ A allele and vitiligo in all subjects (Egger's regression P values $=0.086,0.044$, respectively). The filled circles represent studies that showed publication bias. The diamonds at the bottom of the figure show summary effect estimates before (open) and after (filled) publication bias adjustment.

\section{DISCUSSION}

$T N F-\alpha$ is located within the human leukocyte antigen class III region in chromosome 6 , which has been shown to be the strongest linkage locus for autoimmune diseases. Although RA and vitiligo can have many causes, genetic factors are thought to be involved. $T N F-\alpha-238$ 
$\mathrm{A} / \mathrm{G}$ and $-308 \mathrm{~A} / \mathrm{G}$ polymorphisms may be responsible for RA and vitiligo. The TNF- $\alpha-238$ $\mathrm{A} / \mathrm{G}$ and $-308 \mathrm{~A} / \mathrm{G}$ polymorphisms have been reported to be associated with several autoimmune disorders (Lee et al., 2006). However, studies examining the associations between these polymorphisms and RA or vitiligo have shown conflicting results (Brinkman et al., 1997; Vinasco et al., 1997; van Krugten et al., 1999; Yen et al., 2001; Fabris et al., 2002; Zwiers et al., 2004; Correa et al., 2005; Rodríguez-Carreón et al., 2005; Yazici et al., 2006; Namian et al., 2009; Emonts et al., 2011; Laddha et al., 2012; Salinas-Santander et al., 2012; Al-Harthi et al., 2013; You et al., 2013). Persistent difficulties regarding robust and replicable results in genetic association studies are almost certainly attributable to the small size of the effects of genetic variants, and therefore, a large number of study subjects is required to ensure adequate statistical power, such as a meta-analysis. A previous meta-analysis by Song et al. (2014) indicated that the $T N F-\alpha-308 \mathrm{~A} / \mathrm{G}$ polymorphism was a significant risk factor for RA in Latin Americans but not in the European, Middle Eastern, or Asian populations.

In the present study, we conducted a meta-analysis of previously published data to evaluate the genetic association between the $T N F-\alpha-238 \mathrm{~A} / \mathrm{G}$ and $-308 \mathrm{~A} / \mathrm{G}$ polymorphisms and susceptibility to RA and vitiligo. We found that the $T N F-\alpha-238$ polymorphism was associated with significant susceptibility to RA when all subjects were considered. However, meta-analysis after stratification by ethnicity revealed no association between the $T N F-\alpha-238 \mathrm{~A} / \mathrm{G}$ polymorphism and RA in European, Latin American, and Asian populations. This result may be explained by the small sample size in each group. We could not conduct ethnicity-specific meta-analysis of the $T N F-\alpha-308 \mathrm{~A} / \mathrm{G}$ polymorphism in vitiligo because of the availability of only a single study in some ethnic groups. Instead, we carried out a meta-analysis stratified by geographical continent. Continent-specific meta-analysis revealed that the $T N F-\alpha-308 \mathrm{~A} / \mathrm{G}$ polymorphism is a significant risk factor for vitiligo in Middle Eastern populations. TNF- $\alpha$ acts as a paracrine inhibitor of melanocytes and influences the process of apoptosis in melanocytes, which is considered to be an important susceptibility factor in vitiligo. Thus, our data indicate that the TNF- $\alpha-308$ A/G polymorphism increases the risk of developing vitiligo.

The present study had some limitations. First, publication bias and heterogeneity may have distorted the meta-analyses. Second, the number of subjects and studies included in the ethnicity-specific meta-analyses was small. This study may not have enough power to explore the association between the $T N F-\alpha-238 \mathrm{~A} / \mathrm{G}$ polymorphism and RA in all ethnic groups. Third, we could not perform an ethnic-specific analysis of the $T N F-\alpha-308 \mathrm{~A} / \mathrm{G}$ polymorphism in vitiligo because of the limited number of studies within each ethnic group. Further studies are required in different ethnic populations because the prevalence of the $T N F-\alpha-308 \mathrm{~A} / \mathrm{G}$ polymorphism varies depending on ethnicity. Fourth, the associations between these polymorphisms and disease activities and clinical features should be examined to obtain data stratified by gender or autoantibody status, but such analyses were not possible in this study because of limited or unavailable resources.

In conclusion, this meta-analysis showed that the $T N F-\alpha-238 \mathrm{~A} / \mathrm{G}$ polymorphism was associated with susceptibility to RA, and the $T N F-\alpha-308 \mathrm{~A} / \mathrm{G}$ polymorphism may represent a significant risk factor for vitiligo in Middle Eastern populations. These findings warrant further investigation into the associations between the $T N F-\alpha$ polymorphisms and susceptibility to RA and vitiligo. Studies of a larger scale in populations with different ethnicities are necessary to explore the roles of the polymorphisms of the $T N F-\alpha$ gene in the pathogeneses of RA and vitiligo. 


\section{Conflicts of interest}

The authors declare no conflict of interest.

\section{ACKNOWLEDGMENTS}

Research supported in part by a grant of the Korea Healthcare Technology R\&D Project, Ministry for Health and Welfare, Republic of Korea (\#HI13C2124).

\section{REFERENCES}

Al-Harthi F, Zouman A, Arfin M, Tariq M, et al. (2013). Tumor necrosis factor-alpha and -beta genetic polymorphisms as a risk factor in Saudi patients with vitiligo. Genet. Mol. Res. 12: 2196-2204.

Allen RD (1999). Polymorphism of the human TNF-alpha promoter-random variation or functional diversity? Mol. Immunol. 36: 1017-1027.

Brinkman BM, Huizinga TW, Kurban SS, van der Velde EA, et al. (1997). Tumour necrosis factor alpha gene polymorphisms in rheumatoid arthritis: association with susceptibility to, or severity of, disease? Br. J. Rheumatol. 36: 516-521.

Choi SJ, Rho YH, Ji JD, Song GG, et al. (2006). Genome scan meta-analysis of rheumatoid arthritis. Rheumatology (Oxford) 45: 166-170.

Correa PA, Gomez LM, Cadena J and Anaya JM (2005). Autoimmunity and tuberculosis. Opposite association with TNF polymorphism. J. Rheumatol. 32: 219-224.

D'Alfonso S and Richiardi PM (1994). A polymorphic variation in a putative regulation box of the TNFA promoter region. Immunogenetics 39: 150-154.

DerSimonian R and Laird N (1986). Meta-analysis in clinical trials. Control. Clin. Trials 7: 177-188.

Egger M, Davey Smith G, Schneider M and Minder C (1997a). Bias in meta-analysis detected by a simple, graphical test. BMJ 315: 629-634.

Egger M, Smith GD and Phillips AN (1997b). Meta-analysis: principles and procedures. BMJ 315: 1533-1537.

Emonts M, Hazes MJ, Houwing-Duistermaat JJ, van der Gaast-de Jongh CE, et al. (2011). Polymorphisms in genes controlling inflammation and tissue repair in rheumatoid arthritis: a case control study. BMC Med. Genet. 12: 36.

Fabris M, Di Poi E, D’Elia A, Damante G, et al. (2002). Tumor necrosis factor-alpha gene polymorphism in severe and mild-moderate rheumatoid arthritis. J. Rheumatol. 29: 29-33.

Harris ED, Jr. (1990). Rheumatoid arthritis. Pathophysiology and implications for therapy. N. Engl. J. Med. 322: 1277-1289.

Higgins JP and Thompson SG (2002). Quantifying heterogeneity in a meta-analysis. Stat. Med. 21: 1539-1558.

Laddha NC, Dwivedi M and Begum R (2012). Increased tumor necrosis factor (TNF)-alpha and its promoter polymorphisms correlate with disease progression and higher susceptibility towards vitiligo. PLoS One 7: e52298.

Lee YH, Harley JB and Nath SK (2006). Meta-analysis of TNF-alpha promoter -308 A/G polymorphism and SLE susceptibility. Eur. J. Hum. Genet. 14: 364-371.

Lee YH, Rho YH, Choi SJ, Ji JD, et al. (2007). PADI4 polymorphisms and rheumatoid arthritis susceptibility: a metaanalysis. Rheumatol. Int. 27: 827-833.

Lee YH, Woo JH, Choi SJ, Ji JD, et al. (2010). Associations between osteoprotegerin polymorphisms and bone mineral density: a meta-analysis. Mol. Biol. Rep. 37: 227-234.

Lee YH, Bae SC, Choi SJ, Ji JD, et al. (2011). Associations between vitamin D receptor polymorphisms and susceptibility to rheumatoid arthritis and systemic lupus erythematosus: a meta-analysis. Mol. Biol. Rep. 38: 3643-3651.

Mollet I, Ongenae K and Naeyaert JM (2007). Origin, clinical presentation, and diagnosis of hypomelanotic skin disorders. Dermatol. Clin. 25: 363-371, ix.

Namian AM, Shahbaz S, Salmanpoor R, Namazi MR, et al. (2009). Association of interferon-gamma and tumor necrosis factor alpha polymorphisms with susceptibility to vitiligo in Iranian patients. Arch. Dermatol. Res. 301: 21-25.

Rodríguez-Carreón AA, Zúñiga J, Hernández-Pacheco G, Rodríguez-Pérez JM, et al. (2005). Tumor necrosis factor-alpha -308 promoter polymorphism contributes independently to HLA alleles in the severity of rheumatoid arthritis in Mexicans. J. Autoimmun. 24: 63-68.

Rooney M, David J, Symons J, Di Giovine F, et al. (1995). Inflammatory cytokine responses in juvenile chronic arthritis. Br. J. Rheumatol. 34: 454-460. 
Salinas-Santander M, Díaz-García D, Rojas-Martínez A, Cantú-Salinas C, et al. (2012). Tumor necrosis factor-alpha $-308 \mathrm{G} / \mathrm{A}$ polymorphism is associated with active vitiligo vulgaris in a northeastern Mexican population. Exp. Ther. Med. 3: 893-897.

Song GG, Bae SC, Kim JH and Lee YH (2014). Association between TNF-alpha promoter -308 A/G polymorphism and rheumatoid arthritis: a meta-analysis. Rheumatol. Int. 34: 465-471.

Trajkov D, Mishevska-Perchinkova S, Karadzova-Stojanoska A, Petlichkovski A, et al. (2009). Association of 22 cytokine gene polymorphisms with rheumatoid arthritis in population of ethnic Macedonians. Clin Rheumatol. 28: 1291-1300.

van Krugten MV, Huizinga TW, Kaijzel EL, Zanelli E, et al. (1999). Association of the TNF +489 polymorphism with susceptibility and radiographic damage in rheumatoid arthritis. Genes Immun. 1: 91-96.

Vinasco J, Beraún Y, Nieto A, Fraile A, et al. (1997). Polymorphism at the TNF loci in rheumatoid arthritis. Tissue Antigens 49: 74-78.

Yazici AC, Erdal ME, Kaya TI, Ikizoglu G, et al. (2006). Lack of association with TNF-alpha-308 promoter polymorphism in patients with vitiligo. Arch. Dermatol. Res. 298: 46-49.

Yen JH, Chen CJ, Tsai WC, Lin CH, et al. (2001). Tumor necrosis factor promoter polymorphisms in patients with rheumatoid arthritis in Taiwan. J. Rheumatol. 28: 1788-1792.

You CG, Li XJ, Li YM, Wang LP, et al. (2013). Association analysis of single nucleotide polymorphisms of proinflammatory cytokine and their receptors genes with rheumatoid arthritis in northwest Chinese Han population. Cytokine 61: 133-138.

Zwiers A, Seegers D, Heijmans R, Koch A, et al. (2004). Definition of polymorphisms and haplotypes in the interleukin12B gene: association with IL-12 production but not with Crohn's disease. Genes Immun. 5: 675-677. 